\title{
Legibilidade: Ponto de Apoio para a Comunicação Escrifa
}

\author{
ALDO V. DE MAGALHÃES \\ Prof. de Técnica de Jornal e Periódico e Edição \\ Jornalistica na Universidade de Brasília
}

Quando consultamos uma lista telefônica, podemos ler até mil palavras por minuto. Através de um processo seletivo que elimina o que não queremos encontrar, a identificação dos símbolos gráficos se processa em alta velocidade. Na realidade 0 que fazemos é não tomar conhecimento daquilo que não interessa. Como se procurássemos, correndo por uma estrada, um determinado ponto que antecipadamente soubéssemos assinalado por uma placa verde, por exemplo, ou uma seta azul. Ao estudarmos, no entanto, não será prudente superar o número de duzentas palavras por minuto na leitura que nos conduzirá a novos conhecimentos "permanentes". Se o que buscamos é uma informação séria do tipo da que é oferecida em revistas de conteúdo mais ou menos educativo, podemos, sem prejuízo, acelerar nossa leitura até trezentas palavras por minuto.

Para ler um jornal, onde buscamos informações que no geral não nos interessam em profundidade, ou não representam a busca de um conhecimento permanente, podemos abranger sem prejuízo da compreensão, 500 palavras por minuto. Os índices assinalados, se bem que investigados à base de textos inglêses, parecem válidos quase sem alterações para o português.

\section{DISPOSIÇÃO E PREPARO}

As velocidades mencionadas, integrantes de uma tabela mais extensa sôbre a matéria (Whitaker), são atingidas mediante treinamento. Parece razoável supor que não constituem maioria as pessoas que atingem fàcilmente os índices previstos nos vários tipos de leitura. O êxito recente dos cursos de leitura dinâmica mostra com suficiente eloqüência como nossa leitura é carregada de vícios e se presta ainda a muito polimento e exercício tendente a obter melhores índices de rendimento. 
E preciso observar, no entanto, que apesar dos métodos muito modernos e da grande eficiência da leitura dinâmica, as condições de velocidade em função do objetivo que buscamos na leitura permanecem inalteradas. $O$ estudo exige repetição e tempo de assimilação. Outros tipos de leitura, não.

Este artigo foi originàriamente conteúdo de aulas introdutórias a uma pesquisa de legibilidade em jornais. Partimos então da hipótese de que a maneira de ler um jornal é exercitada com mais freqüência que outros tipos de leitura. As razões parecem óbvias. Assim, é de se presumir, também aproxime-se ela, mais que nos outros casos de uma velocidade ideal de leitura. Inteiramente aplicável a todos os textos que se destinam a oferecer informações a um leitor eventualmente apressado ou interessado em não conservar informações que já tem ou que Ihe pareçam supérfluas por esta ou aquela razão. Com extraordinária freqüência encontramos textos dêsse tipo - ou que deveriam ser dêsse tipo - nas comunicações internas das repartições públicas.

O aviso que se inicia com a declaração sôbre quem é o chefe da repartição que o funcionário freqüenta todo o dia provàvelmente não será lido nesta parte. Começará a merecer a atenção do leitor ao qual se dirige exatamente no ponto em que a "informação útil" tiver início. O estudo dos elementos de legibilidade poderá conduzir as chefias a uma redação mais direta e menos sujeita a eventuais "pontos obscuros" que determinem o não cumprimento de instruções, ou o registro inadequado de alterações normativas.

\section{OS DADOS QUE BUSCAMOS}

No caso do exame das condições de legibilidade de jornais, nosso interêsse fundamental se prende aos fatôres que possam determinar a permanência de nosso leitor como leitor. A maior ou menor eficiência que possa obter na leitura do texto representará sem dúvida o maior ou menor interêsse em continuar preferindo o mesmo veículo de comunicação. No rádio, uma voz desagradável pode ser desligada. A voz ou a imagem na televisão têm o mesmo destino.

Convém, portanto, ter em conta que a eficiência da leitura depende em boa parte da eficiência com que o texto é escrito, tendo em vista a maior facilidade de leitura. Em português, a linguagem ganha um sabor de intimidade e clareza quando a frase é posta na ordem direta. As frases menores parecem preferiveis às frases longas. $E$ as palavras com muitas sílabas oferecem tropeços à leitura rápida. 
Mas o interêsse do leitor não se resume à facilidade de palavras pequenas e de frases curtas. Um péssimo noticiário poderá utilizar frases curtas. Até mesmo onde devesse empregar sentenças mais longas. O estilo, os recursos de expressão, a proximidade da palavra escrita com a expressão oral, o quotidiano, até mesmo a gíria, constituem elementos de valor na construção de frases e períodos. E na elaboração da matéria do jornal.

O preparo da matéria, pelos redatores, pode obedecer a normas segundo as quais, de acôrdo com experiências realizadas, se obtenha um grau de clareza, de legibilidade, bem melhor. O que é importante, no entanto, quando se estudam problemas ligados à legibilidade, é considerar tôdas as possibilidades de aperfeiçoamento. E assim como os catálogos de tipos oferecidos às indústrias gráficas exaltam qualidades de clareza e boa apresentação, o tipo de máquina com que é preparada uma ordem de serviço ou um convite para festa, na repartição, deverá ser levado em conta, juntamente com o que chamamos de correção da frase e limpidez de expressão. Todo o conjunto é que poderá conduzir à boa legibilidade.

Ainda não é possível afirmar que um texto com frases curtas e uso altamente moderado de polissílabos se torne o tipo de leitura preferido pelo leitor padrão de um bom jornal. Outros fatôres deverão sempre ser levados em conta. Êstes, ligados ao uso de pequenas palavras e frases curtas, pesam consideràvelmente na balança.

\section{APRESENTAÇÃO GRÃFICA}

Os melhores autores, quando editados sem cuidado, oferecem dificuldade de leitura. As boas obras literárias são apresentadas em edições onde todos os cuidados são tomados para um impecável efeito gráfico. A escolha do tipo, os claros entre linhas, a disposição dos intertítulos, os cortes e até a numeração das páginas devem ser levados em conta para o resultado harmonioso de conjunto. Para um bom resultado de legibilidade.

Os problemas são bem mais sérios quando se trata de jornal. A utilização de colunas estreitas e tipos claros são elementos valiosos na solução dos problemas de legibilidade. As chamadas de primeira página são feitas, quando se procura obter alto índice de legibilidade, em tipos e blocos adequados a uma leitura ultra-rápida sem prejuizo da compreensão.

A boa técnica da elaboração dos títulos manda evitar a caixa alta e as intercalações bruscas de maiúsculas e minúsculas visando precisamente permitir ao leitor a apreensão do 
conteúdo em apenas uma fixação de olhos. Da mesma forma, as palavras consideradas de mais difícil compreensão não devem aparecer em títulos. $\mathrm{E}$ assim também aquelas que poderiam conduzir a uma interpretação dúbia, embora momentânea.

A simples aplicação das regras básicas de elaboração de títulos talvez pudesse operar uma transformação saudável em muitos textos de documentos oficiais. Com extraordinária freqüência encontramos trechos importantes COMPLETAMENTE ESCRITOS EM MAIÚSCULAS, certamente com o propósito de torná-los mais claros. Pela mesma razão que o leitor reduziu a velocidade de leitura neste texto ao encontrar as quatro palavras com letras maiúsculas, um trecho muito grande escrito assim poderá fazer com que o leitor desista de ler o aviso até o fim. A reprodução de extensos telegramas em quadros de avisos é provàvelmente um bom exemplo do êrro que se comete ao tentar êsse tipo de "clareza". Raramente são lidos. Primeiro, porque seu conteúdo é fàcilmente pressentido a partir do destaque que o envolve. $\mathrm{E}$, segundo, porque é preciso uma grande dose de paciência para manter a atenção de leitura numa forma não usual de apresentação gráfica. Normalmente apenas as iniciais de frase são maiúsculas. E todo o treinamento de leitura, desde nossa infância, foi realizado sôbre esta norma básica. Agora compreendemos também a causa da enorme dificuldade encontrada na leitura de alguns convites bossa-nova onde a acentuação é tão desprezada quanto a norma de utilização de maiúsculas ou as regras de pontuação.

\section{SELEÇÃO DAS PALAVRAS}

Ainda quando empregássemos tipos excelentes, espacejamento adequado e papel de primeira, teríamos contribuído pouco para a clareza do texto se as palavras não fôssem usadas com critério. Muitas palavras têm uma expressão de intimidade. Esta expressão sofre alterações com o tempo e dependem do lugar onde são empregadas. Muitas formas gramaticais criam ambiente de simpatia para com o autor. No comércio, na indústria e certamente nas repartições públicas, existe uma "rotina técnica" que origina uma "gíria técnica" que seria êrro grave desprezar no processo da comunicação escrita. Embora saibamos, e muito freqüentemente possamos "sentir" que palavras usadas na linguagem falada nem sempre são adequadas para a linguagem escrita. A boa seleção de palavras e expressões capazes de estabelecer maior comunicabilidade, entre o autor e o leitor, contribui não apenas para criar maior receptividade ao que se diz, mas ainda para permitir a condição básica de quem pretende se comunicar por escrito: que seja lido. 
Se numa pesquisa de conteúdo podemos dizer de que interêsse cuida o editor prioritàriamente, pesquisando a legibilidade, podemos avaliar de que maneira o editor cuida de levar ao conhecimento do leitor o seu conteúdo.

\section{TROPEÇOS E BARREIRAS}

Uma letra maiúscula no título da notícia oferece barreira à leitura. A palavra totalmente desconhecida no texto pode determinar o abandono da leitura de uma notícia. Mas não são apenas êstes os obstáculos à legibilidade de um texto. A constante utilização de figuras e uma construção invertida de frase podem determinar o cansaço do leitor muito antes de têrmos conseguido atrair sua atenção para a mensagem contida naquilo que escrevemos.

As normas internacionais para notação de trabalhos científicos constituem, certamente, uma proveitosa convenção para o desenvolvimento da pesquisa. Mas, seria inteiramente inadequado pensar na sua aplicação ao texto de um noticiário de jornal e à maioria dos textos com que devemos lidar diàriamente nas repartições públicas, na indústria, nos estabelecimentos de ensino e nas revistas de vulgarização de conhecimentos científicos. $E$ muitos discutem isso quanto a esta última hipótese, embora admitam sem resistência a veracidade dos outros casos.

Numa experiência de aplicação de princípios da estatística ao estudo da produção literária, estão sendo feitas contagens da ocorrência de formas invertidas, adjetivação, emprêgo de negativas, coordenações e subordinações, número de palavras por frase, construções anormais da frase e outros detalhes, para determinar, entre escritores brasileiros, até onde se fizeram legíveis e eficientes no transmitir a mensagem de suas obras literárias.

Passaram pelo crivo que alguns consideram desumano, muitos de nossos autores. Jorge Amado e Érico Veríssimo foram considerados os mais legiveis.

Usando a anormalidade de construção inteligentemente, o bom autor poderá tornar mais efetiva sua mensagem literária. Utilizando com boa técnica os recursos de seu idioma, o jornalista tornará mais direta a informação e mais eficaz, também, sua mensagem do quotidiano: a notícia.

O conteúdo dos documentos oficiais tem muito de notícia. Não há motivo para não transportarmos com bons resultados muitas das observações válidas quanto a jornais, para a ela- 
boração dos textos oficiais. Dificilmente se encontrará razão para âpoiar a necessidade de dureza em tais textos. Elles devem ser lidos e compreendidos. Mais: os dispositivos devem ser cumpridos. Haverá lógica em torná-los duros e antipáticos à primeira leitura? Se o editor do jornal, na concorrência democrática da banca, aspira ao voto renovador de uma nova compra, no dia seguinte, os textos oficiais podem bem aspirar à simpatia que faz o cumprimento da lei agradável e proveitoso. E muito mais quando se sabe que tôda ordem pode ser cumprida ou não dentro de limites nem sempre controláveis pelo administrador.

\section{A PESQUISA DE LEGIBILIDADE}

Muito embora os srs. Flesh e Gunning, nos Estados Unidos, tenham realizado um trabalho de grande valor no que se refere a pesquisas de legibilidade, estabelecendo fórmulas e tabelas de referência, não poderíamos pensar que tudo foi resolvido quanto à técnica de escrever bem para jornal. Ou de preparar textos adequados para as atividades especializadas da indústria, da pesquisa e da administração.

Gunning e Flesh fizeram trabalhos para a United Press International e para a Associated Press e aprofundaram bastante suas pesquisas, ditando normas de redação para as duas organizações.

Quando estêve em Brasilia, após orientar trabalhos que ainda se desenvolvem no Rio Grande do Sul, sôbre pesquisa de linguagem, o professor Jean Roche nos proporcionou valiosa informação de técnicas para estudos de legibilidade. Jean Roche desde muito tempo se tem dedicado à pesquisa das características da língua portuguêsa através do exame da produção literária de nossos melhores autores.

O "Jornal do Brasil", por seu departamento de pesquisa, trabalhou no aperfeiçoamento de padrões de referência para estudo de legibilidade. Foram feitas adaptações de tabelas e índices para a língua portuguêsa. Embora o material não seja de rigor científico é talvez o único de que podemos dispor para estudos 
de legibilidade especificamente aplicados aos textos de noticiário.

As fórmulas conhecidas, os princípios gerais já empregados em outros idiomas e as adaptações que certamente deverão aparecer, permitem um trabalho de fôlego neste campo de conhecimento tão fascinante e de cuja utilidade não se poderá duvidar diante dos resultados proveitosos já verificados nas primeiras experiências.

\section{REFERENCIA BIBLIOGRAFICA:}

WHITAKER PENTEADO - A Técnica da Comunicação Humana JOHN HOHENBERG - Manual de Jornalismo RODRIGUES LAPA - Estilística da Língua Portuguêsa ALMEIDA TÔRRES - Moderna Gramática Expositiva da Língua Portuguêsa

JOAQUIM DOUGLAS - Jornalismo: a Técnica do Título JEAN ROCHE - Aulas na UnB BELUCO MARRA - Pesquisa no Jornal do Brasil RUDOLF FLESH - The Art of Readable 


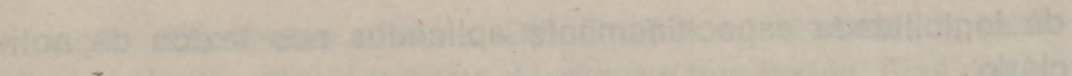

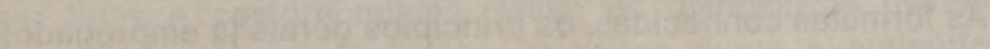

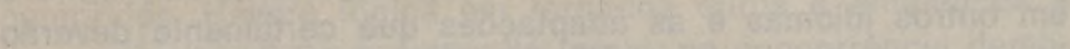

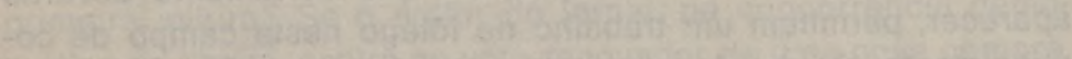

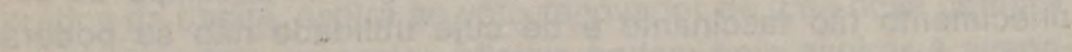

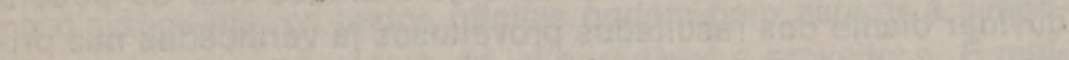

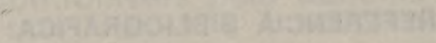

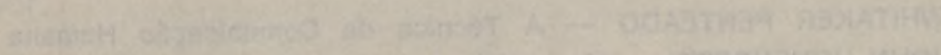

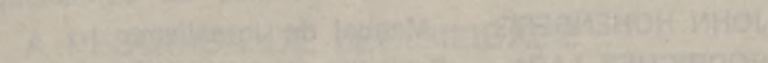

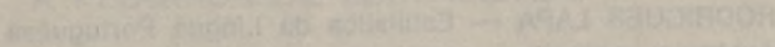

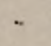

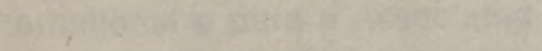

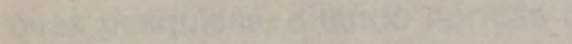

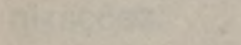

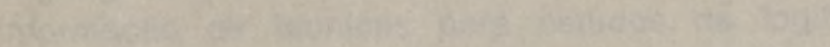

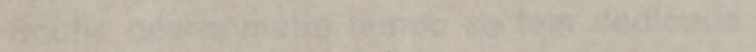

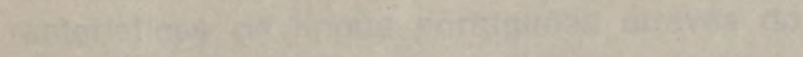

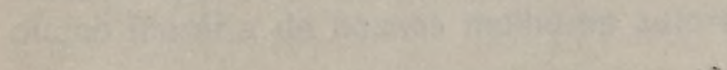

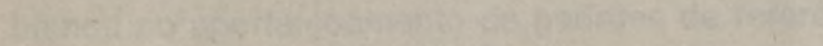

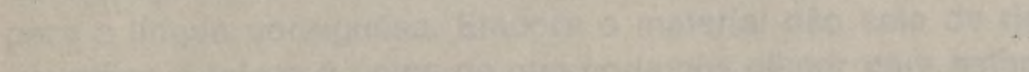

